\title{
Association of Catechol-O- methyltransferase single nucleotide polymorphisms, ethnicity, and sex in a large cohort of fibromyalgia patients
}

\author{
Chee Lee ${ }^{1}$, Ginevra Liptan², Svetlana Kantorovich', Maneesh Sharma ${ }^{3}$ and Ashley Brenton ${ }^{4 *}$ (D)
}

\begin{abstract}
Background: Fibromyalgia (FM) is a complex, centralized pain condition that is often difficult to diagnose and treat. FM is considered to have a genetic background due to its familial aggregation and due to findings from multiple candidate-gene studies implicating catecholaminergic and serotonergic neurotransmitter systems in chronic pain. However, a multi-factorial analysis of both genetic and environmental risk factors is lacking. A better characterization of the interplay of risk factors may assist in understanding the pathophysiology of FM, its clinical course, and assist in early diagnosis and treatment of the disorder.
\end{abstract}

Methods: This retrospective study included 60,367 total participants from 237 clinics across the USA. Of those, 2713 had been diagnosed with fibromyalgia, as indicated by ICD code. Logistic regression was used to test for associations of diagnosed FM in study subjects with COMT SNPs and COMT haplotypes, which were previously found to be linked with pain sensitivity, as well as demographics such as age, sex, and ethnicity. The minor allele frequencies of COMT SNPs in the FM population were compared with 1000 Genomes data using a $\times 2$ test to determine significant deviations from the estimated population allelic frequencies.

Results: FM diagnosis was strongly associated with sex, age, and ethnicity. Females, those between 49 and 63 years, and non-Caucasians were at higher risk of FM. Females had 1.72 increased odds of FM $\left(p=1.17 \times 10^{-30}\right)$. African-Americans were 1.52 times more likely to have a diagnosis of FM compared to Caucasians $\left(p=3.11 \times 10^{-12}\right)$. Hispanics were less likely to have a diagnosis of FM compared to Caucasians $\left(p=3.95 \times 10^{-7}\right)$. After adjusting for sex and ethnicity, those in the low age group and mid age group had $1.29\left(p=1.02 \times 10^{-5}\right)$ and $1.60\left(p=1.93 \times 10^{-18}\right)$ increased odds of FM, respectively, compared to the high age group, where age was categorized by tertile (low $(<49)$, mid (49-63), and high (> 63)). The COMT haplotypes associated with pain sensitivity were not associated with FM, but African-Americans were 11.3 times more likely to have a high pain sensitivity COMT diplotype, regardless of FM diagnosis. However, the minor alleles of COMT SNPs rs4680, rs4818, rs4633 and rs6269 were overrepresented in the FM population overall, and varied when compared with ethnically-similar populations from 1000 Genomes.

(Continued on next page)

\footnotetext{
* Correspondence: abrenton@mycroftbioanalytics.com

${ }^{4}$ Mycroft Bioanalytics, Inc., 299 South Main Street, Suite 2300, Salt Lake City,

UT 84111-2278, USA

Full list of author information is available at the end of the article
}

(c) The Author(s). 2018 Open Access This article is distributed under the terms of the Creative Commons Attribution 4.0 International License (http://creativecommons.org/licenses/by/4.0/), which permits unrestricted use, distribution, and reproduction in any medium, provided you give appropriate credit to the original author(s) and the source, provide a link to the Creative Commons license, and indicate if changes were made. The Creative Commons Public Domain Dedication waiver (http://creativecommons.org/publicdomain/zero/1.0/) applies to the data made available in this article, unless otherwise stated. 
(Continued from previous page)

Conclusions: This is the largest study, to date, that examines demographic and genetic associations of FM in a diverse population. While pain sensitivity-associated COMT haplotypes were not found to be directly associated with FM diagnosis, the minor alleles that make up the COMT haplotypes were overrepresented in the FM population, suggesting a role of COMT in FM. Future studies are needed to elucidate the exact role of COMT variation in widespread pain conditions, such as FM. Clinically, this information can be used to provide insight into the pathways underlying FM and to identify those at greater risk of developing FM.

Keywords: Fibromyalgia, Chronic pain, Precision medicine, Genomics, Catechol-O-methyltransferase

\section{Background}

Fibromyalgia (FM) is a chronic illness that affects an estimated $5.4 \%$ of the US population, and is 2.3 times more prevalent in women than men [1]. FM is characterized by widespread pain, tenderness and fatigue, and is notoriously challenging to diagnose and treat. Patients suffering from FM report a low quality of life [2], and are 3.4 times more likely to suffer from major depressive disorder than those without FM [3].

FM is difficult to diagnose and treat because it manifests a diverse range of symptoms that affect multiple body systems, and it is frequently accompanied by comorbid disease. FM is often a diagnosis of exclusion after other possible conditions have been treated without success and ruled out. Common FM symptoms include pain sensitivity, chronic fatigue, muscle tenderness, mental fog, sleep disturbances, and digestive issues. These same symptoms are also reported in other illnesses, such as temporomandibular disorder, irritable bowel syndrome, and mental disorders $[4,5]$. In fact, FM co-occurs with these conditions frequently [6]. FM is also often associated with other diseases like hypothyroidism [7], rheumatoid arthritis, and systemic lupus erythematosus [8], as well as psychiatric diseases, such as major depressive disorder, and mood and anxiety disorders [4]. Current diagnostic criteria for FM rely solely on subjective measures, as there is currently no accepted objective testing. The 1990 ACR diagnostic criteria require presence of pain upon pressure applied to at least 11 of 18 specific tender points, and the updated 2010 criteria use a symptom survey as a diagnostic tool. The development of an objective genetic biomarker would significantly improve our ability to diagnose fibromyalgia.

The multi-system pathology of FM stems in part from autonomic nervous system dysfunction, in particular excess sympathetic activity which has been well demonstrated in heart-rate variability studies $[9,10]$. Although incompletely understood, abnormal catecholaminergic signaling has been identified in the pathogenesis of FM and central sensitization [11]. COMT genetic variations that result in excess levels of catecholamines may promote development of chronic pain via stimulation of adrenergic receptors in the peripheral and central nervous systems $[12,13]$. The autonomic nervous system likely plays a role in regulation of fibromyalgia pain, as functional MRIs in FM subjects with higher levels of sympathetic nervous system activity demonstrated more temporal summation of pain [14]. Variations in COMT activity are one factor that may contribute to the complex interaction of autonomic nervous system and pain regulation.

Catecholamines (i.e. dopamine, epinephrine, norepinephrine) are key neurotransmitters in both pain-inhibiting and pain-initiating pathways, depending on gene expression factors, and cell type $[15,16]$. Several gene-candidate studies have examined serotonergic, dopaminergic, and catecholaminergic markers as major players in central sensitization and FM pain [17-29]. In particular, the missense variant val $^{158}$ met in catecholamine-O-methyltransferase gene (COMT) single nucleotide polymorphism (SNP), rs4680, results in significantly reduced catecholaminergic turnover, which has been shown to be associated with FM [22-29]. However, some studies in non-Caucasian populations have conflicting results [30, 31], showing only weak association of rs4680 with FM, or stronger association with other COMT SNPs, suggesting the association of COMT SNPs may be ethnic group specific.

Haplotypes consisting of COMT SNP rs4680, rs6269, rs4633, and rs4818, have also been shown to be associated with pain sensitivity [32,33], although it is unclear if those haplotypes have a role in chronic widespread pain, like FM. Nicholl et al. [34] did not find a link with COMT haplotypes and FM in two separate cohorts comparing pain-free individuals to those with FM; however, both cohorts consisted of Caucasians and one cohort exclusively of men. Conversely, Martinez-Jauand et al. [24], in an age-matched case-control study of patients with British ancestry, found FM patients to more likely have COMT haplotypes corresponding to higher pain sensitivity. Studies of COMT in FM thus far have been limited to small cohorts and specific populations. The focus of our study was to evaluate both COMT polymorphisms and phenotypic associations with FM in order to identify defining factors in diagnosis. This is the largest study thus far to examine associations of COMT SNPs and COMT haplotypes with FM. 


\section{Methods}

This multi-center, observational clinical study (study protocols 2015/11/1, HS-15-00191, 2016/07/26, 1JUL14-62CR, 1,309,306, 20,152,748, 1JAN15-26, 1JAN15-20CR, 1JAN15$14 \mathrm{CR}$ ) was reviewed, approved, and overseen by Solutions IRB, an institutional review board licensed by the United States Department of Health and Human Services, Office for Human Research Protections. All participants signed informed consent forms prior to data collection.

\section{Study participants}

Participants in the study were recruited from 237 clinics across the US, including orthopedic, spinal, pain management, and internal medicine clinics. Recruitment also included the criterion that the administrating medical professional deemed the genetic test was medically necessary to assess risk of FM. In total, the study comprised of 60,367 participants. Among the study participants, a group of 2713 individuals with FM (a 4.5\% diagnosis rate) were identified using the International Statistical Classification of Diseases and Related Health Problems (ICD)-9 series code 729.1 for "myalgia and myositis" and ICD-10 series code M79.7 for "fibromyalgia." All participants in the study who had complete genetic data for the COMT single nucleotide polymorphisms (SNPs), rs6269, rs4633, rs4818, and rs4680, were included in downstream analysis. A control group of participants, referred to as non-FM, were identified as those who had not been diagnosed with FM via ICD codes. Non-FM participants were also filtered by ICD codes to exclude conditions that were comorbid with FM (such as osteoarthritis and temporomandibular joint disorders), as well as chronic conditions and pain diagnoses, to reduce the rate of undiagnosed FM. The non-FM group included 32,141 participants in total.

\section{DNA analysis}

DNA sample collection and genotyping

The methods were described previously [35].

\section{COMT haplotyping}

Haplotypes for COMT enzymatic activity were identified according to Diatchenko, et al. [18]. The three haplotypes for COMT SNPs rs6269, rs4633, rs4818, and $r s 4680$ are as follows: high pain sensitivity haplotype (HPS) as A_C C_G, average pain sensitivity (APS) as A_T_C_A, and low pain sensitivity (LPS) as G_C_G_G. LPS corresponds to higher COMT enzymatic activity, APS to average activity, and HPS to lower activity. To verify haplotypes, the expectation maximization algorithm implemented by the haplo.em function in the $\mathrm{R}$ package haplot.stats [36] was used to empirically compute maximum likelihood estimates of haplotype probabilities. Only subjects with the major diplotypes (LPS/LPS, LPS/APS, APS/APS, LPS/HPS, APS/ $\mathrm{HPS}$, and HPS/HPS) were included in the association testing. Among the COMT diplotypes, high pain sensitivity corresponds to HPS/HPS or APS/HPS diplotypes, and low pain sensitivity corresponds to an LPS/LPS diplotype.

\section{Statistical analysis \\ Associations with demographics}

Logistic regression was used to model the log odds of FM compared to the non-FM group in association with sex, ethnicity, and age. To increase power and provide clinically relevant interpretations, age was re-categorized by tertile: low $(<49)$, mid (49-63), and high (>63). All statistical analyses were performed in $\mathrm{R}$ version 3.2.5.

\section{Genetic associations with FM}

To reduce bias due to patient recruitment and enrollment in the study, the FM group was compared to individuals in the 1000 Genomes Project [37] from US populations $(n=224)$ to assess genetic associations with the COMT SNPs. This allowed testing for significant deviations of allele frequencies in the FM group compared to the general population. A $X^{2}$ test of proportions was used to determine if the observed minor allele frequencies (MAFs) in the FM group significantly deviated from the 1000 Genomes MAFs of the respective population with similar demographics. For $r s 4680$, the minor allele corresponds to the val ${ }^{158}$ met variant (major>minor: $\mathrm{G}>\mathrm{A}$ ). Minor alleles of the other COMT SNPs are $r s 6269$ (A > G), rs4633 (C > T), and rs4818 (C > G).

\section{Results}

\section{Demographics FM study participants}

FM was found to be significantly more common in certain demographics (Tables 1, 2, and Fig. 1). FM is well known to have a higher occurrence in women $[38,39]$, which was also observed in this study. The FM group $(n=2713)$ was comprised of $71.6 \%$ females compared with $58.5 \%$ females in the non-FM group $(n=32,141)$, which corresponded to a 1.72 increased odds of FM $\left(p=1.17 \times 10^{-30}\right.$; Tables 1,2 and Fig. 1). The overall average age of the study population was 55.6 years (standard deviation $=15.5$ ). The average age in FM and non-FM groups were 55.7 and 54.9 years, respectively. Considering the wide distribution of ages in the study, age was re-categorized by tertile: low $(<49)$, mid (49-63), and high (>63). On average, study patients in the low and mid age group had 1.29 ( $p=$ $\left.1.02 \times 10^{-5}\right)$ and $1.60\left(p=1.93 \times 10^{-18}\right)$ increased odds of FM, respectively, compared to the high age group, after adjusting for gender and ethnicity (Table 2). Interestingly, the ethnicity associated with the highest diagnosis rate of FM was African-American. After adjusting for age group and sex, African-Americans were 1.52 times more likely to have a diagnosis of FM compared to Caucasians ( $p=$ $3.11 \times 10^{-12}$;Table 2 and Fig. 1). Hispanics were less likely to have a diagnosis of FM compared to Caucasians ( $p=$ 
Table 1 Demographics of study participants and US populations from the 1000 Genomes Project

\begin{tabular}{|c|c|c|c|c|}
\hline Group & Mean Age & Ethnicity & $n$ (\% Total) & $\%$ Females \\
\hline \multirow[t]{5}{*}{ Fibromyalgia (FM) } & 54.9 & All: & $2713(100 \%)$ & $72 \%^{a}$ \\
\hline & & African-American: & $380(14 \%)^{b}$ & $71 \%$ \\
\hline & & Caucasian: & $1779(66 \%)^{b}$ & $71 \%$ \\
\hline & & Hispanic: & $130(4.8 \%)$ & $71 \%$ \\
\hline & & Other: & $34(1.3 \%)$ & $65 \%$ \\
\hline \multirow[t]{5}{*}{ Non-Fibromyalgia (Non-FM) } & 55.7 & All: & $32,141(100 \%)$ & $59 \%$ \\
\hline & & African-American: & $2863(8.9 \%)^{b}$ & $65 \%$ \\
\hline & & Caucasian: & $21,807(68 \%)^{b}$ & $58 \%$ \\
\hline & & Hispanic: & $2515(7.8 \%)$ & $57 \%$ \\
\hline & & Other: & $2028(6.3 \%)$ & $60 \%$ \\
\hline \multirow[t]{4}{*}{1000 Genomes (US populations) } & N/A & All: & $224(100 \%)$ & $52 \%$ \\
\hline & & African-American: & $61(27 \%)$ & $57 \%$ \\
\hline & & Caucasian: & 99 (44\%) & $51 \%$ \\
\hline & & Hispanic: & $64(29 \%)$ & $50 \%$ \\
\hline
\end{tabular}

${ }^{\mathrm{a}} \%$ Females in FM is significantly increased as compared to \% females in the Non-FM group $\left(p=1.17 \times 10^{-30}\right)$

$\mathrm{b}_{\%}$ African-Americans is significantly increased as compared to \% of Caucasians in the Non-FM group $\left(p=3.11 \times 10^{-12}\right)$

$3.95 \times 10^{-7}$ ). There was no difference in the distribution of ethnicity or sex between the non-FM group and the group of study patients that were excluded from the non-FM group due to FM comorbidities and pain diagnoses.

\section{Frequency of COMT SNP minor alleles in FM group}

Overall, the minor alleles of the COMT SNPs were overrepresented in the FM group compared to 1000 Genomes (Table 3). Additionally, each of the four COMT SNPs had significantly different minor allele frequencies (MAFs) in at least one subpopulation of the FM group than what was observed in the general population by the 1000 Genomes

Table 2 Adjusted odds ratios (OR) associated with each demographic feature

\begin{tabular}{llll}
\hline Demographic & Model $\beta$ & Adj. OR & $P$-value \\
\hline Age - vs. high (>63 yrs) & & & \\
$\quad$ Mid (49-63 yrs) & 0.469 & 1.60 & $1.02 \times 10^{-5}$ \\
Low (<49yrs) & 0.255 & 1.29 & $1.93 \times 10^{-18}$ \\
$\begin{array}{l}\text { Gender - vs. males } \\
\text { Females }\end{array}$ & 0.541 & 1.72 & $1.17 \times 10^{-30}$ \\
$\begin{array}{l}\text { Ethnicity - vs. Caucasians } \\
\text { African-Amer. }\end{array}$ & 0.421 & 1.52 & $3.11 \times 10^{-12}$ \\
Hispanic & -0.475 & 0.62 & $3.95 \times 10^{-7}$ \\
Other & -0.635 & 0.53 & $1.78 \times 10^{-6}$ \\
\hline
\end{tabular}

Logistic regression modelling the log odds of FM in the FM group compared to the non-FM group showed significant differences in age, gender, and ethnicities. Model $\beta$ coefficients are the log (adjusted ORs). An individual in the mid age group, female, and African-American would have the most increased odds of FM (adjusted OR = 4.18) compared to someone who is in in the high age group, male, and Caucasian
Project (Table 3). Differences were observed in Caucasian males, who exhibited significantly lower MAF of $r s 6269$, and African-American females, who exhibited significantly higher MAF of rs6269 (Fig. 2a). Only Caucasians exhibited significantly higher MAF of $r s 4633$ (Fig. 2b). Caucasian males and African-American females showed significantly lower MAF of $r s 4818$ (Fig. 2c). Both female and male Caucasians had higher MAF of $r$ 44680. In African-Americans, only females had higher MAF of $r s 4680$ (Fig. 2d). MAFs of the COMT SNPs were not significantly different between the FM group and the non-FM group (Additional file 1: Table S1).

\section{Low and high pain sensitivity COMT diplotypes in study participants}

COMT haplotypes correspond to low (LPS), average (APS), or high (HPS) pain sensitivity phenotypes due to differences in COMT enzymatic activity [32]. Other haplotypes were also observed, but at low frequencies, did not have statistically significantly high haplotype likelihoods and were not associated with pain sensitivity in the Diatchenko et al. study [32]. In total, 2409 (89\%) of FM patients and 29,170 (91\%) control patients had diplotypes in combination of the three major COMT haplotypes: LPS/LPS, LPS/APS, APS/APS, LPS/HPS, APS/HPS, and HPS/HPS (Additional file 2: Figure S1). There were no statistically significant associations of COMT haplotypes or diplotypes with FM diagnosis in the FM group compared to the non-FM group. There was an association of COMT haplotypes or diplotypes with ethnicity groups: African-Americans were 11.3 times more likely to have COMT diplotype corresponding 

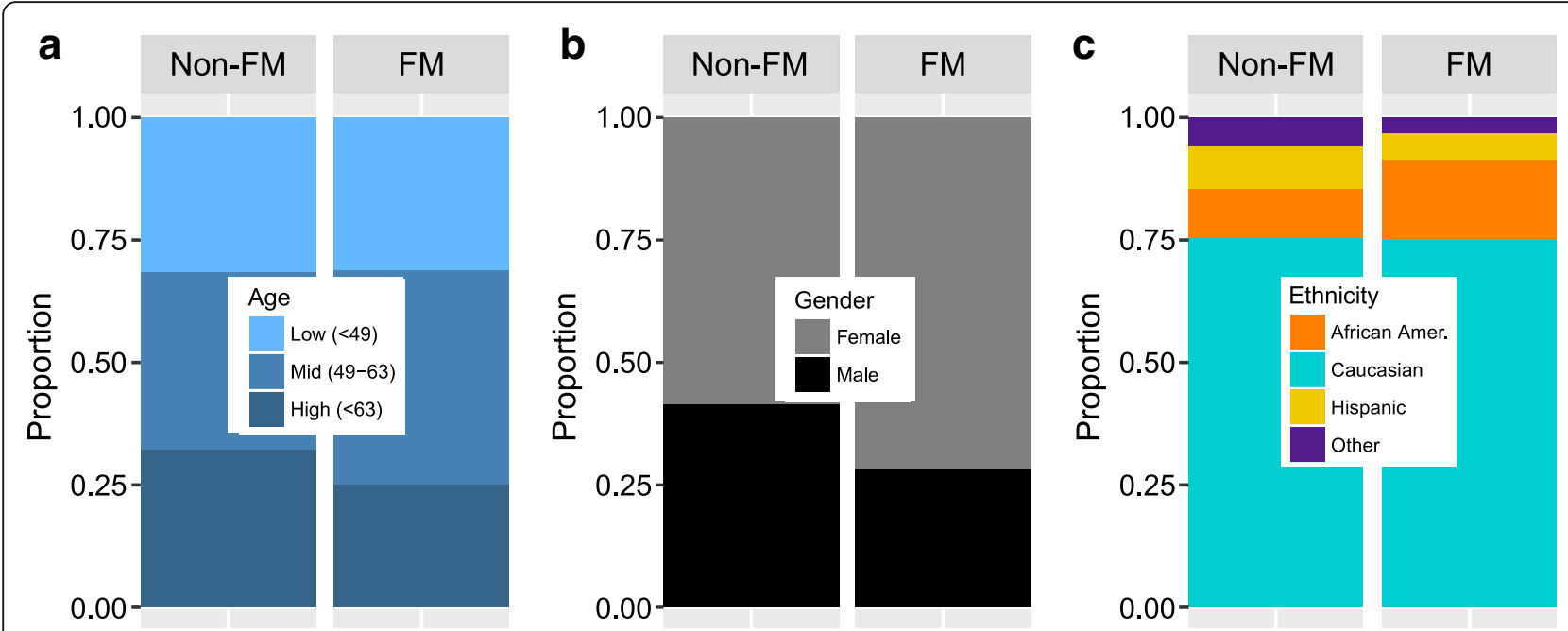

Fig. 1 Distribution of FM diagnosis by (a) age, (b) sex, and (c) ethnicity. Those diagnosed with FM were more likely to be in the middle age tertile (49-63), female, and African-American compared to the non-FM group. Adjusted odds ratios associated with each specific demographic is shown in Table 1

with high pain sensitivity than Caucasians, regardless of whether or not they were diagnosed with $\mathrm{FM}(p=7.27 \times$ $10^{-249}$; Fig. 3).

\section{Discussion}

Studies examining the association between COMT and fibromyalgia have largely focused on a single functional polymorphism, rs4680 or val ${ }^{158}$ met, $[17,18,21]$ which reduces enzymatic activity by 3 - to 4 -fold, and is associated with an increased risk of chronic pain [19, 23, 40-44]. Our study demonstrates that the minor allele of $r s 4680$ occurs in higher frequency in FM subjects compared with population controls from the 1000 Genomes project. However, the SNP was not associated with a diagnosis of FM in this study. Other meta-analyses have both shown and refuted associations between this SNP, indicating additional variables exist that influence the susceptibility to FM. Therefore, we evaluated the association of fibromyalgia with a multi-SNP haplotype, evidenced to be more predictive of COMT enzymatic activity, and associated with a $>20$-fold difference. Common COMT haplotypes were not specifically associated with FM either, suggesting that COMT enzymatic activity and catecholamine levels, per se, are not driving the development of fibromyalgia pain. We did note that while none of the common pain sensitivity-associated COMT haplotypes were associated with FM, the presence of minor alleles of all four of the COMT SNPs examined herein (ie: rs4680 A + rs6269 G + rs4633 T + rs4818 G is not one of the commonly described COMT haplotypes) was associated with an FM diagnosis, but would be rare.
Rather, this study shows the risk of developing FM was based on interactions with sex and ethnicity: the presence of one or more copies of a COMT SNP minor allele is increased in those with FM in certain demographics of ethnicity and sex. African-Americans had higher risk of a FM diagnosis than Caucasians or Hispanics, and AfricanAmerican women had the highest risk overall. AfricanAmerican men and women were also 11 times more likely than their Caucasian counterparts to have a COMT diplotype corresponding to high pain sensitivity regardless of whether or not they were diagnosed with FM. Therefore, COMT SNPs may provide information on the likelihood of FM when used in combination with other clinicallyvalidated measures, such as tender points, and, as demonstrated in this study, phenotypic measures, such as ethnicity and sex. This information can be used clinically to more accurately diagnose FM early, instead of a diagnosis of exclusion.

More studies are needed to elucidate the relationship between pain sensitivity and centralized pain disorders, such as FM, but the results of this study - the largest of its kind - support a multifactorial evaluation for FM diagnosis, including ethnicity. Interestingly, the criteria used to diagnose fibromyalgia were developed in a cohort that was predominately comprised of Caucasian females [45]; this study emphasizes the need for refinement with regard to sex and/or ethnicity. However, our study relies on ICD codes to classify FM patients. Additional criteria such as tender points on patients, and detailed medical history would help to improve identification of those who truly have FM and those studies are underway. While every effort was made to exclude those with chronic pain 
Table 3 Minor allele frequencies (MAFs) of COMT SNPs in subjects diagnosed with fibromyalgia (FM) compared with those of US populations from the 1000 Genomes Project (1000G-US)

\begin{tabular}{|c|c|c|c|c|c|}
\hline \multirow[t]{2}{*}{ SNP/Population } & \multicolumn{5}{|c|}{ Minor Allele Frequency } \\
\hline & 1000G-US & FM Group & Direction & Model $\beta$ & $P$-value \\
\hline$r s 6269(A>G)$ & 0.36 & 0.39 & $\uparrow$ & -0.03 & $2.40 \times 10^{-6}$ \\
\hline African-American & 0.34 & 0.38 & $\uparrow$ & -0.04 & 0.023 \\
\hline Caucasian & 0.44 & 0.41 & $\downarrow$ & 0.03 & $1.69 \times 10^{-4}$ \\
\hline Hispanic & 0.27 & 0.28 & & -0.01 & 0.580 \\
\hline Females & 0.34 & 0.39 & $\uparrow$ & -0.05 & $1.69 \times 10^{-12}$ \\
\hline African-American & 0.29 & 0.38 & $\uparrow$ & -0.09 & $6.04 \times 10^{-7}$ \\
\hline Caucasian & 0.41 & 0.40 & & 0.01 & 0.472 \\
\hline Hispanic & 0.28 & 0.27 & & 0.01 & 0.831 \\
\hline Males & 0.39 & 0.40 & & -0.01 & 0.540 \\
\hline African-American & 0.40 & 0.36 & & 0.04 & 0.145 \\
\hline Caucasian & 0.47 & 0.42 & $\downarrow$ & 0.05 & 0.002 \\
\hline Hispanic & 0.25 & 0.30 & & -0.05 & 0.347 \\
\hline rs4633 (C > T) & 0.41 & 0.47 & $\uparrow$ & -0.06 & $1.08 \times 10^{-22}$ \\
\hline African-American & 0.32 & 0.33 & & -0.01 & 0.583 \\
\hline Caucasian & 0.46 & 0.51 & $\uparrow$ & -0.05 & $3.04 \times 10^{-8}$ \\
\hline Hispanic & 0.40 & 0.43 & & -0.03 & 0.348 \\
\hline Females & 0.41 & 0.48 & $\uparrow$ & -0.07 & $7.16 \times 10^{-20}$ \\
\hline African-American & 0.33 & 0.33 & & 0 & 0.838 \\
\hline Caucasian & 0.48 & 0.52 & $\uparrow$ & -0.04 & $6.25 \times 10^{-5}$ \\
\hline Hispanic & 0.38 & 0.44 & & -0.06 & 0.064 \\
\hline Males & 0.41 & 0.46 & $\uparrow$ & -0.05 & $8.18 \times 10^{-5}$ \\
\hline African-American & 0.31 & 0.32 & & -0.01 & 0.695 \\
\hline Caucasian & 0.45 & 0.49 & $\uparrow$ & -0.04 & 0.009 \\
\hline Hispanic & 0.42 & 0.39 & & 0.03 & 0.601 \\
\hline rs4818 (C > G) & 0.32 & 0.36 & $\uparrow$ & -0.04 & $2.15 \times 10^{-9}$ \\
\hline African-American & 0.21 & 0.19 & & 0.02 & 0.185 \\
\hline Caucasian & 0.44 & 0.40 & $\downarrow$ & 0.04 & $1.69 \times 10^{-5}$ \\
\hline Hispanic & 0.24 & 0.27 & & -0.03 & 0.245 \\
\hline Females & 0.31 & 0.36 & $\uparrow$ & -0.05 & $1.17 \times 10^{-9}$ \\
\hline African-American & 0.23 & 0.19 & $\downarrow$ & 0.04 & 0.024 \\
\hline Caucasian & 0.41 & 0.40 & & 0.01 & 0.356 \\
\hline Hispanic & 0.25 & 0.26 & & -0.01 & 0.672 \\
\hline Males & 0.33 & 0.36 & $\uparrow$ & -0.03 & 0.006 \\
\hline African-American & 0.19 & 0.21 & & -0.02 & 0.573 \\
\hline Caucasian & 0.47 & 0.41 & $\downarrow$ & 0.06 & $1.19 \times 10^{-4}$ \\
\hline Hispanic & 0.23 & 0.30 & & -0.07 & 0.201 \\
\hline$r s 4680(G>A)$ & 0.39 & 0.47 & $\uparrow$ & -0.08 & $5.62 \times 10^{-31}$ \\
\hline African-American & 0.27 & 0.31 & $\uparrow$ & -0.04 & 0.006 \\
\hline Caucasian & 0.46 & 0.51 & $\uparrow$ & -0.05 & $1.36 \times 10^{-7}$ \\
\hline Hispanic & 0.40 & 0.44 & & -0.04 & 0.187 \\
\hline Females & 0.40 & 0.48 & $\uparrow$ & -0.08 & $4.82 \times 10^{-23}$ \\
\hline African-American & 0.29 & 0.31 & & -0.02 & 0.145 \\
\hline
\end{tabular}


Table 3 Minor allele frequencies (MAFs) of COMT SNPs in subjects diagnosed with fibromyalgia (FM) compared with those of US populations from the 1000 Genomes Project (1000G-US) (Continued)

\begin{tabular}{llllll}
\hline SNP/Population & Minor Allele Frequency & & & \\
\cline { 2 - 6 } & 1000G-US & FM Group & Direction & Model $\beta$ & -0.04 \\
\hline Caucasian & 0.48 & 0.52 & $\uparrow$ & -0.06 & $1.67 \times 10^{-4}$ \\
Hispanic & 0.39 & 0.45 & $\uparrow$ & -0.07 & 0.088 \\
Males & 0.39 & 0.46 & $\uparrow$ & -0.07 & $4.35 \times 10^{-8}$ \\
African-American & 0.25 & 0.32 & $\uparrow$ & -0.04 & 0.025 \\
Caucasian & 0.45 & 0.49 & 0 & 0.012 \\
Hispanic & 0.41 & 0.41 & & 0.988 \\
\hline
\end{tabular}

Comparisons that are statistically significant $(p \leq 0.05)$ are indicated with direction of increased or decreased frequency of MAF. Model $\beta$ coefficients are the effect sizes. Differences between groups delineated by both sex and ethnicity are graphically shown in Fig. 2

conditions, comorbid conditions and undiagnosed FM from the control group, it is possible that such an individual who was being treated for acute pain may have been included in the control group. Thus, a clearly defined group of individuals without FM or comorbidities, such as chronic pain, would serve as a more definitive control for the FM group. Overall, our study can be strengthened with an increased number of participants and stricter criteria for FM diagnosis.

\section{Conclusions}

This is the largest study to date to examine the role of genetics, sex and ethnicity in FM. This study builds upon previous work demonstrating an association between the
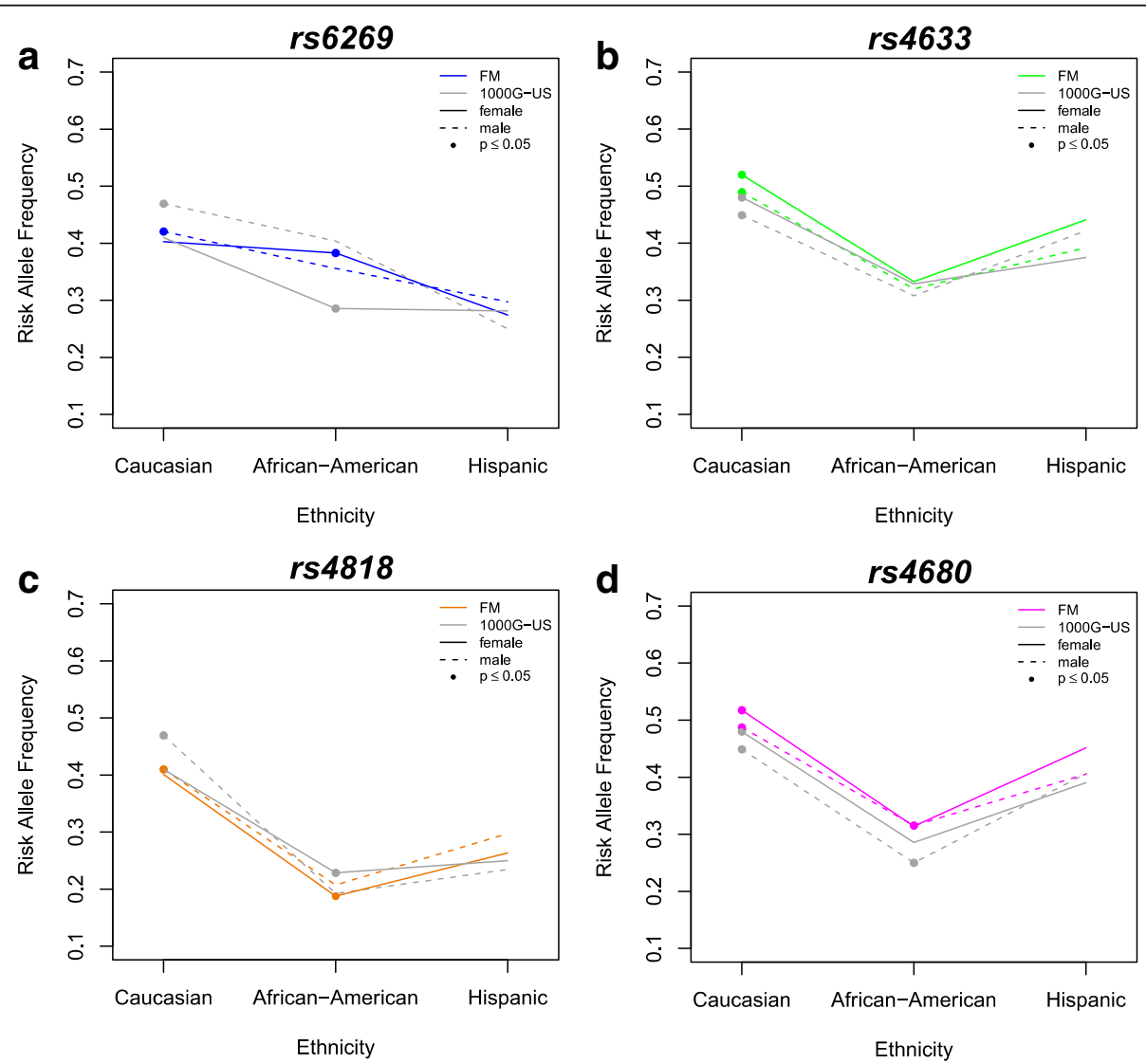

Fig. 2 Comparing individuals with a diagnosis of fibromyalgia (FM) to US populations from the 1000 Genomes Project (1000G-US), the minor allele frequencies (MAFs) of each COMT SNP vary by sex and ethnicity. MAF of each COMT SNP are represented by colored lines in the FM group and by gray lines in the US populations from the 1000 Genomes Project. Solid lines denote females and dashed lines denote males. Significant differences $(p \leq 0.05)$ between the FM and 1000 Genomes subpopulations are represented by filled circles 

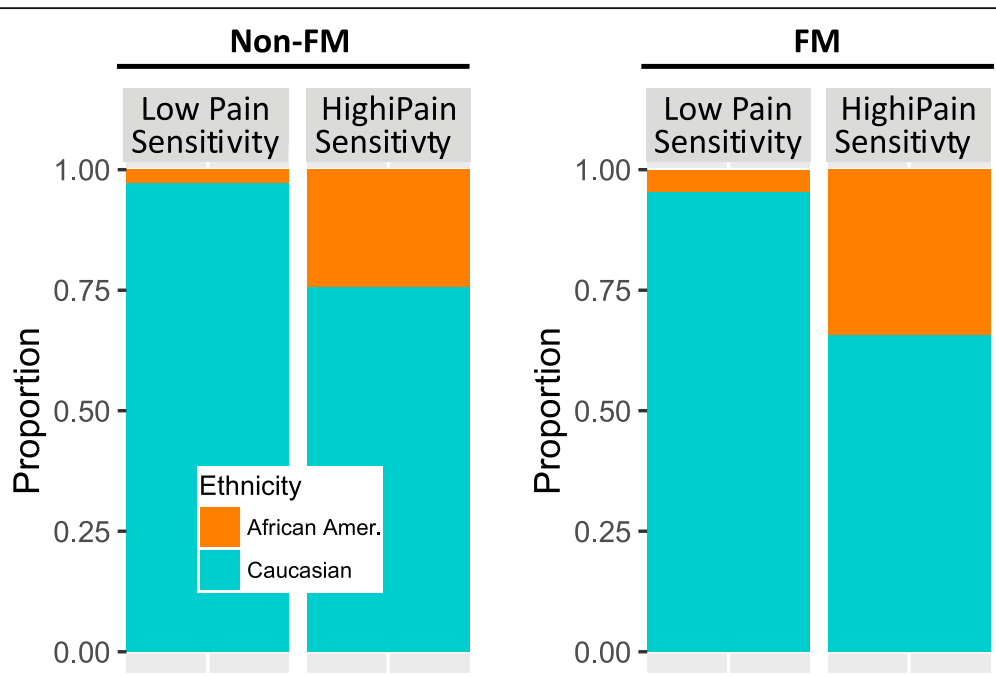

Fig. 3 Differences in observed COMT diplotypes in African-Americans and Caucasians. Among those diagnosed with FM, African-Americans had 11.3 times increased odds of having a COMT diplotype corresponding to high pain sensitivity than low pain sensitivity, regardless of whether or not they were diagnosed with FM ( $p=7.27 \times 10^{-249}$, adjusted for sex and age)

COMT gene and chronic pain conditions. Setting it apart, however, is the multi-ethnic nature of the cohort, which explores the association between African-American ancestry, high pain sensitivity and FM diagnosis. This information can be used to refine clinical diagnostic criteria, provide information that allows clinicians to treat FM as a first diagnosis, decreasing time between the appearance of symptoms and diagnosis, and inform future studies of the importance in considering sex and ethnicity when conducting genetic association studies.

\section{Additional files}

Additional file 1: Table S1. Overall minor allele frequencies of COMT SNPs in FM, 1000 Genomes, and non-FM groups. (DOCX 13 kb)

Additional file 2: Figure S1. Distribution of COMT diplotypes among FM and non-FM groups. (DOCX $69 \mathrm{~kb}$ )

\section{Abbreviations}

APS: Average pain sensitivity; COMT: Catechol-O-methyltransferase; FM: Fibromyalgia; HPS: High pain sensitivity; ICD: International Statistical Classification of Diseases and Related Health Problems; LPS: Low pain sensitivity; SNP: Single nucleotide polymorphism

\section{Acknowledgements}

The authors gratefully acknowledge the patients involved in the study, without whose contribution this work would not be possible. The authors gratefully acknowledge Corrine Unruh, PhD, for her help in drafting this manuscript.

\section{Ethics, consent and permissions}

This multi-center, observational clinical study (study protocols 2015/11/1, HS-15-00191, 2016/07/26, 1JUL14-62CR, 1,309,306, 20,152,748, 1 JAN15-26, 1JAN15-20CR, 1JAN15-14CR) was reviewed, approved, and overseen by Solutions IRB, an institutional review board licensed by the United States Department of Health and Human Services, Office for Human Research Protections. All participants signed informed consent forms prior to data collection.

\section{Funding}

This study was funded by Mycroft Bioanalytics, Inc.

\section{Availability of data and materials}

All data is available upon request from $\mathrm{CL}$ or $\mathrm{AB}$.

\section{Authors' contributions}

$C L$ analyzed the data and drafted, revised and edited the manuscript. $A B$ determined the experimental design of the study, drafted the manuscript, revised and edited the manuscript. SK wrote the study protocol, planned the experimental design, revised and edited the manuscript. GL drafted the manuscript and provided subject matter expertise. MS revised the manuscript, provided subject matter expertise for the study design, collected data. All authors read and approved the final manuscript

\section{Consent for publication}

Not applicable.

\section{Competing interests}

This study was sponsored by Mycroft Bioanalytics, Inc. AB is an employee of Mycroft Bioanalytics. CL and SK are former employees of Proove Biosciences. MS was a principal investigator of a Proove-sponsored study.

\section{Publisher's Note}

Springer Nature remains neutral with regard to jurisdictional claims in published maps and institutional affiliations.

\section{Author details}

${ }^{1}$ Proove Biosciences, Inc., Irvine, CA, USA. ${ }^{2}$ The Frida Center for Fibromyalgia, Portland, OR, USA. Interventional Pain Institute, Baltimore, MD, USA. ${ }^{4}$ Mycroft Bioanalytics, Inc., 299 South Main Street, Suite 2300, Salt Lake City, UT 84111-2278, USA.

Received: 14 November 2017 Accepted: 9 November 2018 Published online: 12 December 2018

\section{References}

1. Jones GT, Atzeni F, Beasley M, Flüß E, Sarzi-Puttini P, Macfarlane GJ. The prevalence of fibromyalgia in the general population: a comparison of the American College of Rheumatology 1990, 2010, and modified 2010 classification criteria. Arthritis \& Rheumatology. 2015;67:568-75. 
2. Patten SB, Beck C, Kassam A, JVA W, Barbui C, Metz LM. Long-term medical conditions and major depression: strength of association for specific conditions in the general population. Can J Psychiatr. 2005;50(4):195-202.

3. Neumann L, Buskila D. Epidemiology of fibromyalgia. Curr Pain Headache Rep. 2003;7(5):362-8.

4. Arnold LM, Hudson Jl, Keck PE, Auchenbach MB, Javaras KN, Hess EV. Comorbidity of fibromyalgia and psychiatric disorders. J Clin Psychiatry. 2006; 67(8):1219-25

5. Wolfe F, Häuser W. Fibromyalgia diagnosis and diagnostic criteria. Ann Med. 2011;43(7):495-502.

6. Maixner W, Fillingim RB, Williams DA, Smith SB, Slade GD. Overlapping Chronic Pain Conditions: Implications for Diagnosis and Classification. J Pain. 2016:17(9):T93-T107.

7. Garrison RL, Breeding PC. A metabolic basis for fibromyalgia and its related disorders: the possible role of resistance to thyroid hormone. Med Hypotheses. 2003;61(2):182-9.

8. Weir PT, Harlan GA, Nkoy FL, Jones SS, Hegmann KT, Gren LH, Lyon JL. The incidence of fibromyalgia and its associated comorbidities: a population-based retrospective cohort study based on International Classification of Diseases, 9th Revision codes. J Clin Rheumatol. 2006;12(3):124-8.

9. Martinez-Lavin M, Hermosillo AG. Autonomic nervous system dysfunction may explain the multisystem features of fibromyalgia. Semin Arthritis Rheum. 2000;29(4):197-9.

10. Cohen $\mathrm{H}$, et al. Autonomic dysfunction in patients with fibromyalgia: application of power spectral analysis of heart rate variability. Semin Arthritis Rheum. 2000;29(4):217-27.

11. Russell IJ, Vaeroy H, Javors M, Nyberg F. Cerebrospinal fluid biogenic amine metabolites in fibromyalgia/fibrositis syndrome and rheumatoid arthritis. Arthritis Rheum. 1992;35(5):550-6.

12. Khasar SG, et al. Vagal modulation of nociception is mediated by adrenomedullary epinephrine in the rat. Eur J Neurosci. 2003;17(4):909-15.

13. Donello JE, et al. A peripheral adrenoceptor-mediated sympathetic mechanism can transform stress-induced analgesia into hyperalgesia. Anesthesiology. 2011;114(6):1403-16.

14. Kim J, et al. The somatosensory link in fibromyalgia: functional connectivity of the primary somatosensory cortex is altered by sustained pain and is associated with clinical/autonomic dysfunction. Arthritis Rheumatol. 2015;67(5):1395-405.

15. Nielsen LA, Henriksson KG. Pathophysiological mechanisms in chronic musculoskeletal pain (fibromyalgia): the role of central and peripheral sensitization and pain disinhibition. Best Pract Res Clin Rheumatol. 2007:21(3):465-80.

16. Smith SB, et al. Epistasis between polymorphisms in COMT, ESR1, and GCH1 influences COMT enzyme activity and pain. Pain. 2014;155(11):2390-9.

17. Diatchenko L, Slade GD, Nackley AG, Bhalang K, Sigurdsson A, Belfer I, Goldman D, Xu K, Shabalina SA, Shagin D, Max MB, Makarov SS, Maixner W. Genetic basis for individual variations in pain perception and the development of a chronic pain condition. Hum Mol Genet. 2005;14(1):135-43.

18. Diatchenko L, Nackley AG, Slade GD, Bhalang K, Belfer I, Max MB, Goldman D, Maixner W. Catechol-O-methyltransferase gene polymorphisms are associated with multiple pain-evoking stimuli. Pain. 2006;125(3):216-24.

19. Vargas-Alarcón G, Fragoso JM, Cruz-robles D, Vargas A, Vargas A, LaoVilladóniga Jl, García-Fructuoso F, Ramos-Kuri M, Hernández F, Springall R, Bojalil R, Vallejo M, Martínez-Lavín M. Catechol-O-methyltransferase gene haplotypes in Mexican and Spanish patients with fibromyalgia. Arthritis Res Ther. 2007;9(5):R110.

20. Finan PH, Zautra AJ, Davis MC, Lemery-Chalfant K, Covault J, Tennen $\mathrm{H}$. Genetic influences on the dynamics of pain and affect in fibromyalgia. Health Psychol. 2010;29(2):134-42.

21. Martínez-Jauand M, Sitges C, Rodríguez V, Picornell A, Ramon M, Buskila D, Montoya P. Pain sensitivity in fibromyalgia is associated with catechol-Omethyltransferase (COMT) gene. Eur J Pain. 2012;17(1):16-27.

22. Lee $\mathrm{YH}$, Kim JH, Song GG. Association between the COMT Val158Met polymorphism and fibromyalgia susceptibility and fibromyalgia impact questionnaire score: a meta-analysis. Rheumatol Int. 2015;35(1):159-66.

23. Desmeules J, Chabert J, Rebsamen M, Rapiti E, Piguet V, Besson M, Dayer P, Cedraschi C. Central pain sensitization, COMT Val158Met polymorphism, and emotional factors in fibromyalgia. J Pain. 2014;15(2):129-35.

24. Martinez-Jauand $M$, et al. Pain sensitivity in fibromyalgia is associated with catechol-O-methyltransferase (COMT) gene. Eur J Pain. 2013;17(1):16-27.

25. Tammimaki A, Mannisto PT. Catechol-O-methyltransferase gene polymorphism and chronic human pain: a systematic review and metaanalysis. Pharmacogenet Genomics. 2012;22(9):673-91.
26. Finan $\mathrm{PH}$, et al. Genetic influences on the dynamics of pain and affect in fibromyalgia. Health Psychol. 2010;29(2):134-42.

27. Finan $\mathrm{PH}$, et al. COMT moderates the relation of daily maladaptive coping and pain in fibromyalgia. Pain. 2011;152(2):300-7.

28. Cohen $\mathrm{H}$, et al. The relationship between a common catechol-O-methyltransferase (COMT) polymorphism val(158) met and fibromyalgia. Clin Exp Rheumatol. 2009: 27(5):S51-6.

29. Gursoy S, et al. Significance of catechol-O-methyltransferase gene polymorphism in fibromyalgia syndrome. Rheumatol Int. 2003;23(3):104-7.

30. Vargas-Alarcon G, et al. Catechol-O-methyltransferase gene haplotypes in Mexican and Spanish patients with fibromyalgia. Arthritis Res Ther. 2007; 9(5):R110

31. Park DJ, et al. Association between catechol-O-methyl transferase gene polymorphisms and fibromyalgia in a Korean population: a case-control study. Eur J Pain. 2016:20(7):1131-9.

32. Diatchenko L, et al. Catechol-O-methyltransferase gene polymorphisms are associated with multiple pain-evoking stimuli. Pain. 2006:125(3):216-24.

33. Diatchenko $L$, et al. Genetic basis for individual variations in pain perception and the development of a chronic pain condition. Hum Mol Genet. 2005; 14(1):135-43.

34. Nicholl Bl, et al. No evidence for a role of the catechol-O-methyltransferase pain sensitivity haplotypes in chronic widespread pain. Ann Rheum Dis. 2010;69(11):2009-12.

35. Farah REA. Evaluation of a predictive algorithm that detects aberrant use of opioids in an addiction treatment Centre. Journal of Addiction Research \& Therapy. 2017:8(2)

36. Lake SL, et al. Estimation and tests of haplotype-environment interaction when linkage phase is ambiguous. Hum Hered. 2003;55(1):56-65.

37. Auton A, et al. A global reference for human genetic variation. Nature. 2015; 526(7571):68-74.

38. Branco JC, et al. Prevalence of fibromyalgia: a survey in five European countries. Semin Arthritis Rheum. 2010;39(6):448-53.

39. Mas AJ, et al. Prevalence and impact of fibromyalgia on function and quality of life in individuals from the general population: results from a nationwide study in Spain. Clin Exp Rheumatol. 2008;26(4):519-26.

40. Tammimäki A, Männistö PT. Catechol-O-methyltransferase gene polymorphism and chronic human pain: a systematic review and meta-analysis. Pharmacogenet Genomics. 2012;22(9):673-91.

41. Gursoy S, Erdal E, Herken H, Madenci E, Alaşehirli B, Erdal N. Significance of catechol-O-methyltransferase gene polymorphism in fibromyalgia syndrome. Rheumatol Int. 2003;23(3):104-7.

42. Matsuda JB, Barbosa FR, Morel LJ, França Sde C, Zingaretti SM, da Silva LM Pereira AM, Marins M, Fachin AL. Serotonin receptor (5-HT 2A) and catecholO-methyltransferase (COMT) gene polymorphisms: triggers of fibromyalgia. Rev Bras Reumatol. 2010;50(2):141-9.

43. Cohen $H$, Neumann L, Glazer Y, Ebstein RP, Buskila D. The relationship between a common catechol-O-methyltransferase (COMT) polymorphism val(158) met and fibromyalgia. Clin Exp Rheumatol. 2009:27(5):S51-6.

44. Barbosa FR, Matsuda JB, Mazucato M, de Castro França S, Zingaretti SM, da Silva LM, Martinez-Rossi NM, Júnior MF, Marins M, Fachin AL. Influence of catechol-O-methyltransferase (COMT) gene polymorphisms in pain sensibility of Brazilian fibromialgia patients. Rheumatol Int. 2012;32(2):427-30.

45. Wolfe F, et al. The prevalence and characteristics of fibromyalgia in the general population. Arthritis Rheum. 1995;38(1):19-28.

Ready to submit your research? Choose BMC and benefit from:

- fast, convenient online submission

- thorough peer review by experienced researchers in your field

- rapid publication on acceptance

- support for research data, including large and complex data types

- gold Open Access which fosters wider collaboration and increased citations

- maximum visibility for your research: over $100 \mathrm{M}$ website views per year

At BMC, research is always in progress.

Learn more biomedcentral.com/submissions 